\title{
TRAINING KEY TO ELECTRICAL SYSTEMS MAINTENANCE
}

\author{
Christopher Teal, Eclypse International, Inc., Corona, CA \\ William Larsen, Federal Aviation Administration, Moffett Field, CA
}

\begin{abstract}
Aging wiring has been identified as a national concern. This paper identifies why wiring installed on legacy aircraft has taken center stage and suggests a planned maintenance approach to enhance wiring safety, improve electronic system performance and reliability. The industry must be encouraged into an awareness of the criticality of electronic systems health. The industry must also become cognizant of the technical and operational issues that govern electronic systems reliability. Several alternatives for improving avionics systems performance will be discussed.
\end{abstract}

With proper training and the common usage of advanced diagnostic/prognostic/verification NDT tooling and repair procedures many of the wiring problems will become non-issues. As the technology issues are understood so too will the fire and wire event safety issues [1].

Testing for systems performance, systems trends, and systems useful life must be understood and incorporated into avionics systems diagnostics and prognostics processes. Clearly stated the entire electrical and electronic system must be baselined at the time of component manufacture and after systems installation on the aircraft. When delivered to the operator the same systems must be condition monitored throughout their life until the aircraft is retired. At the time ownership of the aircraft is passed to the operator the baseline records must also be passed for the operator to have a starting point for his condition-monitoring program. This is fundamental to carrying out the requirements of the condition based maintenance (CBM) program for avionics. Tools that are in common use today only provides connectivity and conductivity information of the wiring system and leave the repairman in the dark as to what is wrong if the system does not perform as designed. We are no longer operating in the days of the vacuum tube. The RE is left with insufficient information to understand the systems functioning. The more advanced NDT systems on the market add fault location, insulation degradation (wire insulation cracking, voids, and chafing information and insulation voltage breakdown strength), system conformity and some degree of prognostics. This information adds knowledge to the systems physical condition and helps in the diagnostics. It also is very useful in determining if parts of the wiring system needs replacement and assists in performing that job [2 - 4].

However, few systems on the market today begin to approach this capability. Until our diagnostic and prognostic tools provide systems performance related information to the operator the requirements for an adequate CBM program cannot be met. However, by doing so dramatically reduces maintenance costs, improves safety and reliability. By transferring to a true condition based maintenance (CBM) program will effect a gross reduction in avionics systems failure rates and strongly contribute to meeting our goal of near zero avionics systems failures [5].

The ability to assess a given technology and judge whether it has become obsolete is necessary in today's world. It's obvious that today's testing equipment for wire systems is obsolete and desperately needs upgrading. It is not so obvious that a system engineering approach must be used to judge partial system obsolescence and possibly a good portion of the electronic system itself, not just the wiring judged obsolescent. Component parts non-availability and obsolete functionality usually cause electronic systems obsolescence [6].

As electronic systems reach higher operating frequencies the NDT and analysis equipment must keep pace to define component characteristics and how frequency and degradation of the equivalent circuit affect the systems performance. Systems modeling capabilities must be included within the test equipment not only to quantify system performance, but also to define and monitor stability margins and trend information for the wire

\section{U.S. Government work not protected by U.S. Copyright}


and avionics circuits. This measures the true health of the system [7].

To have available for the RE tradesman the basic systems performance and stability information including LRU/LRM functional circuit charts, diagrams and electrical performance trends and prognostics would greatly assist him in the performance of his duties. The value of this is in the ability to anticipate failure of flight critical and flight essential systems and a reduction in accident rates by preventing any system failure from taking place that could become a contributing factor in an accident.

\section{Introduction}

At the time of original manufacturer and each time the aircraft goes through depot maintenance the aircraft wiring and electronic systems should be condition monitored. This practice has been well proven in structural life management by the Air Force. As the aircraft ages the same systems need to be condition monitored as part of a condition based maintenance (CBM) program. Electronic system monitoring is usually accomplished during the $\mathrm{C}$ and $D$ checks (intermediate or depot). The time to do so is usually no more than 3 days for the entire aircraft and less with experience and knowledge of trends. By obtaining base line data and monitoring trends it is possible to plan for maintenance actions instead of responding to a systems failure or potential experiencing an in-flight fire or wire event [8].

\section{The Following Is Where Wiring Is Today}

In July 1998 the FAA published their aging non-structural plan. The following statement is included in the plan: Current maintenance practices do not adequately address wiring components (wire, wire bundles, connectors, clamps, ground, shielding) or their effect on electronic systems. Inspection criteria are too general. Typically a zonal inspection task card for wiring states: "Perform a general inspection". Important details pertaining to unacceptable conditions are lacking. Airlines report shortcomings in the manufacture maintenance and repair manual on wire. The current arrangement of standard practices makes it difficult for an aircraft maintenance technician to locate and extract the pertinent and applicable data necessary to effect a satisfactory repair. Wire replacement is not adequate. Under current maintenance philosophy wire in conduit is not inspected. Onsite inspection and reporting indicate many examples of improper installation and repair of wiring. A review of incidence reports and maintenance records indicate that current reporting systems lack visibility for wire making it difficult to identify wire failures. These difficulties $\bullet \bullet$ can be overcome by development and use of nondestructive test (NDT) tools to assess the state of wiring in aircraft.

This paper describes some of the degradation taking place in wiring, all-be-it unnoticed during normal operations over the useful life of the aircraft. What happens when a technology becomes obsolete, why training at all levels is "KEY" to arrive at a solution to the stated issues concerning aircraft wiring and systems performance and why systems' engineering is necessary to arrive at that solution [2 \& 14].

\section{Knowledgeable Industry Observers Predict the Future}

"Automated electronics systems inspection equipment should be developed that removes much of the tedium of the inspection, leaving the task of decision making to the human. Today inspection procedures are the weak link." - NTSB member

"One thing the airline industry should learn from the studies of aging aircraft wire systems is the need to rush NDT to the forefront of the maintenance efforts. It would save money and ease concerns about the safety of older aircraft." Aviation Week and Space Technology

"Although the Navy has done wonders in demonstrated visual wire inspection can dramatically reduce in-flight fire and wire related events, other, more sophisticated methods of examining aircraft wiring is the great hope of industry. We haven't touched the surface of what can be used to inspect aircraft wiring noninvasively." Delta Airlines (in Air \& Space)

Table 1, although antidotal has been derived from information and data spontaneously provided by responsible management, practitioners and tradesmen from both commercial carriers and DOD professionals. This data and information carries a clear message from aircraft conceptual design to 
retirement. Further study of table 1 , suggests training as "KEY" if there is to be any hope for improving the status of aging aircraft avionics wiring systems. Further analysis suggests:

1) Seldom should a fault repeat after the first visit through a heavy maintenance facility. Particularly for the same aircraft type, kind and location. This suggests a feedback system reporting to the manufacturer; certification entity and repair shop based on facility capability and aircraft scheduling. Kits are often used in the field and depot to correct necessary design changes.

Table 1. Antidotal Causation Of Electrical Faults

Percent Specifics Concerning Wiring Faults Faults

\begin{tabular}{|l|l|}
\hline $90 \%$ & $\begin{array}{l}\text { Faults repeated aircraft to aircraft of a } \\
\text { single type by kind \& location }\end{array}$ \\
\hline $10 \%$ & $\begin{array}{l}\text { Fault types that are seldom encountered } \\
\text { and hard to detect }\end{array}$ \\
\hline $80 \%$ & Faults that are human induced \\
\hline $25 \%$ & $\begin{array}{l}\text { Effectiveness of visual inspection } \\
\text { Effectiveness of } \text { advanced } \text { wire } \\
\text { inspection techniques }\end{array}$ \\
\hline $20 \mathrm{X}$ & $\begin{array}{l}\text { The number of times a fault may have to } \\
\text { be repaired until it is correct using } \\
\text { today's technology }\end{array}$ \\
\hline
\end{tabular}

2) Faults seldom encountered or hard to detect require advanced diagnostic/prognostic NDT tooling for detection and monitoring to track systems performance and perform repairs during depot maintenance. Using today's testing tools and maintenance practices detection of a fault prior to failure is difficult at best (Figure 1).

3) With proper training in wire husbandry practices, advanced diagnostics /prognostics, mitigation, repair, and verification human induced faults will become negligible. Human induced faults are a byproduct of an attitude of fit and forget. To reduce wiring to a non-issue relative to fire and wire events requires assistance from all trades involved with wiring from the designer, wire manufacturer, certification specialists, installers and RE tradesman as appropriate. This includes historical database mining and avionics conceptual functional drawings and text. Load distributions, signal, coax, fiber optic wiring will each require a slight adjustment of the different NDT tool. One fits all is an unrealistic conclusion, as the software needs adjustment and different adapters are required to interface with each level of the electrical and electronic systems.

4) Current standards for signal wire and power distribution systems and communications media with sufficient bandwidth and linear dynamic range for high-speed computer communications needs to be brought into a condition of relevancy and implemented for new construction. Usually documentation is found to be 20 to 40 years behind leading edge technology and not all required will be looked at as being relevant [10].

5) When a repair needs to be accomplished over several times something is wrong with the system of repair. Verification is to stop parts change outs and improper repairs.

6) Lack of cross-fertilization of new technologies from other industries has contributed to the opening of a substantial gap between modem electronic systems design/ performance requirements and aircraft wiring. Understanding these technologies by the aircraft designer, certification specialist, DER and the operator's RE trades will contribute to making electrical/electronic troubleshooting straight forward and is a must where future avionics design is concerned.

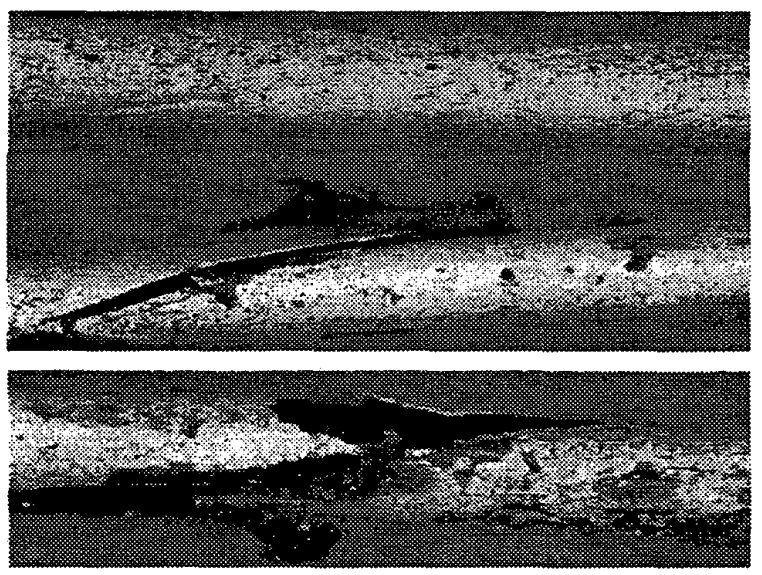

Figure 1. This Type Of Fault Or Risk Of Fire Need Not Be Tolerated Any Longer. A VSWRefectometer Can Identify And Locate It In A Few Minutes 


\section{Training and Who Needs Training}

In fact all aircraft related trades require training concerning wire system husbandry. A series of seminars will shortly be available that starts with a 4-day awareness session for all. Followed by a 5 or 9 day session broken up into specific trades, covering the relevant subjects and providing hands on experience. This training needs repeating every two years at a minimum and should be brought in house after the first or second seminar attended.

Wire/Systems Husbandry in the Classroom

Training continues to be key to electronic systems reliability. Hands on training using advanced NDT tooling on commercial aircraft avionics is available today. The FAA has used new technology training seminars for their certification specialists in the 1980s for software, systems performance and HIRF coupling into electronics. Today systems have reached a stage of complexity that most REs can't relate to systems performance or able to see into an electronic system to judge if that system can perform as designed. Even the designers us specialized software tools to understand how their circuit works particularly when the circuit's frequency of operation is above $300 \mathrm{MHz}$. That software is PSPICE [9].

\section{Awareness Seminar Classroom:}

2 days - Awareness training for all aircraft related personnel including managers

3 days - For the aircraft related trades people

- Simplified phenomenology: chemical, physical, electrical, system performance, etc.

- Simplified Diagnostics

- " Prognostics

- " Repair Procedures

- " Verification

- Basics of electrical engineering and the wire set (power, signal, coax, etc)

- Why systems engineering - the need to include the whole system

- The basic tool set \& how it operates (hands on operation of actual test equipment)
- What the tool set will offer including database analysis

- Developing a testing plan for a subpart of the aircraft or system (requirements)

- Setup \& conducting the test (on aircraft if desired)

- Interpretation \& analysis of real data in the classroom

- New technology soon to be available

- Records keeping (electronic media)

\section{Technical Seminar Classroom}

Wire, Insulation And Frequency: Electrical insulation used on aircraft wiring is known to deteriorate from a number of environmental, chemical, electrical and physical processes that are related in one way or another to the molecular structure of the insulation polymer and the environmental stress encountered during installation and aircraft normal operations. As the physical and chemical properties of the wire system deteriorate due to the environment similar degradation takes place in the electrical properties. Detailed examination of the wire degradation phenomenon has been well documented by various contributors to the technical journals and conference authors for the IEEE Society of Dielectrics and Electrical Insulation. Raychem has also provided similar information to the Navy in their report Investigation of Polyimide Wire Insulation Cracking Phenomenon. At the systems level the IEEE/AIAA Digital Avionics Systems Conference addresses electronic and electrical equipment. From these sources it's recognized that all polymer-based insulation degrades from the time of manufactured at a rate dependent on various combinations of:

- Operational environment

- Human interaction

- Design and application

Most electronic circuits that we use everyday are inherently and mathematically considered having lumped circuit elements and the wires connecting them are considered to have perfect conductors. This assumption works well for low frequency applications. Lumped circuit elements have the desirable feature that they introduce no phase shift into the circuit resulting from propagation delays. The amount of phase shift depends on the electrical circuit length. This shift 
directly affects the phase relationship between current and voltage and system stability. Above 300 $\mathrm{MHz}$ real world component characteristics, distributed parameters and phase/gain margins start to become critical from the standpoint of systems performance and systems stability [10].

Where $\lambda \geq 10 \mathrm{~m}$, the lumped element concept is almost always valid. In the UHF region and above, where $\lambda \leq 1 \mathrm{~m}$ and physical component size can represent a significant fraction of a wavelength, the wire and electrical components show distributed effects in one way or another. In this region circuit stability must be looked at on a case-by-case basis. Distributed circuit parameters must be assumed when [11]:

- Circuit impedance is so low that the resistance in the wire becomes proportionally significant

- The operating frequency (fo) is great enough that the length of the interconnecting wires is a fraction greater than 0.1 of the wavelength or when the wiring circuits are responding as a transmission line.

\section{Direct Current Instrumentation}

Alternating Current Analog

Twisted pair *

Digital bus *

Digital, not a bus *

Synchro, $2 \& 3$ phase *

Emergency ground bus

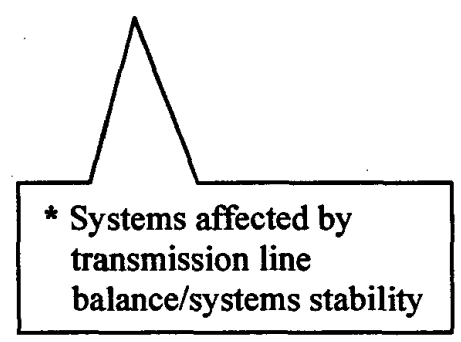

Figure 2. High-Speed Data Transfer Media*
Inspection Tools and Processes Must Meet the Needs of the System Being Inspected

The avionics system technology must complement the inspection system technology. Today the usual wire inspection system is visual, only $25 \%$ effective, and the VOM and meg-ohm meter have been far outpaced by systems technology. Repair records are filed as non-indexed paper and need to be put in electronic form. Far better and more useful methods and equipment for electronic systems diagnostics are on the market. Figures 1 through 9 of [12] show a few examples of advanced diagnostic test equipment. This equipment works well for diagnostics, some prognostics and verification. However, full integration with a complete fleet database, data mining capability and fleet records keeping, complete avionics systems conceptual diagrams and descriptive text are still in the prototype stage [13].

\section{Advanced Tooling and Why It Gives You More}

A VSWReflectometer is a good example of an advanced technology electrical tool for looking into the wire system to observe how it is operating. To be able to observe from the inside the operation of a modern set of electronics is essential to measure its performance. This measure far exceeds the methods in use in the field today. The Reflectometer transmits a known electrical wave shape into the circuit and anticipates a delayed reflection. If the reflected waveform is similar and can be overlaid to other waveforms from identical systems of other aircraft of the same type that system is operationally functioning. This test take only 5 minutes, ascertains performance levels and locates faults, if present. Figure 3A, 3B, 3C \& 4 [13, 14 \& 15].

In the event the waveform is reflected back in an unrecognizable form the test equipment is able to recognize which part of the system tested is faulted. The input waveform, in this case is a sine wave. If a fault is encountered software in the SWReflectometer is able from the information reflected define the location the fault is from the point of measurement. The electronic repairman (RE) clicking and dragging the circuit schematic on his laptop computer sees the feet and inches the fault is away; the probable failed component. Typical examples of failed components are 
corroded connector, wire corrosion, defective antenna or broken wire. Fault detection only takes a few minutes and the fix not much longer. A far cry from easter-egging the system for up to 20 times to fix the problem.

It also must be noted there are a number of functions wire performs on the aircraft. Several examples of this are power distribution, systems control and signal. Signal breaks down into seven different functions of which four operate as a transmission line at elevated frequency. This separates both the type of test the wire must undergo to determine whether it represents a hazard to the safety of the aircraft or simply the functionality of the systems it connects. Typically this type of wire operates at low voltage and high frequency. It can be tested for connectivity, conductivity and compliance to design. Each test represents a two-ended test but does not represent whether the wire performs its intended design purpose. The closest test that performs this function is a single ended test conducted by a reflectometer that locates faults along the wire's length. This generally is able to test for performance by standing waves testing. However, systems performance can't be tested for when the system is not connected to the wire. To the wire not connected to the LRU or LRM it must be tested as a transmission line with the load, line and source impedance is known.

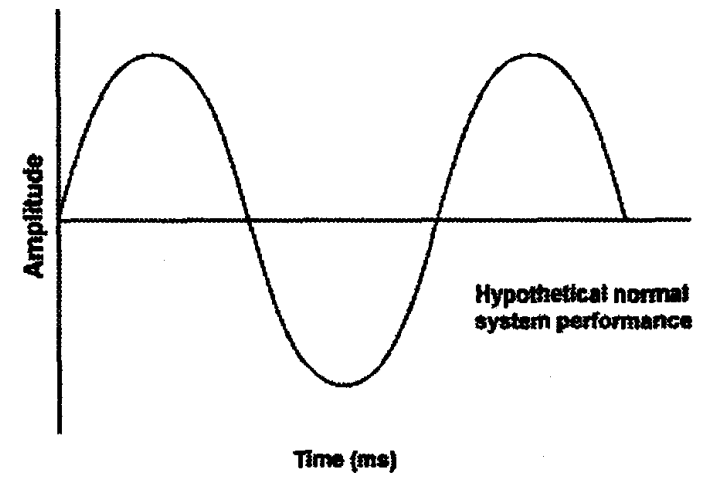

Figure 3A. System Tested To Performance Standard: Sum Total of Acceptable Systems

Total anticipated useful life for this example system is 12 years based on desired level of system reliability, risk analysis and decision theory. Hypothetical example case (Figure 4) uses data from the Navy P-3 zonal wire degradation study to

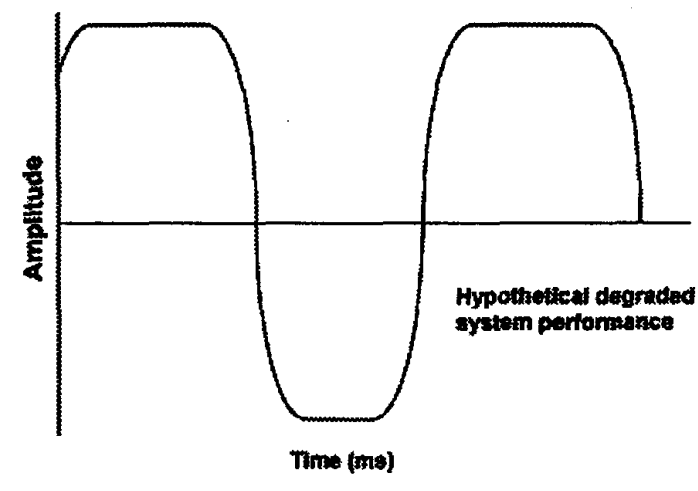

Figure 3B. System Degraded Operationally, Distorted VSWReflection See Figure 4.

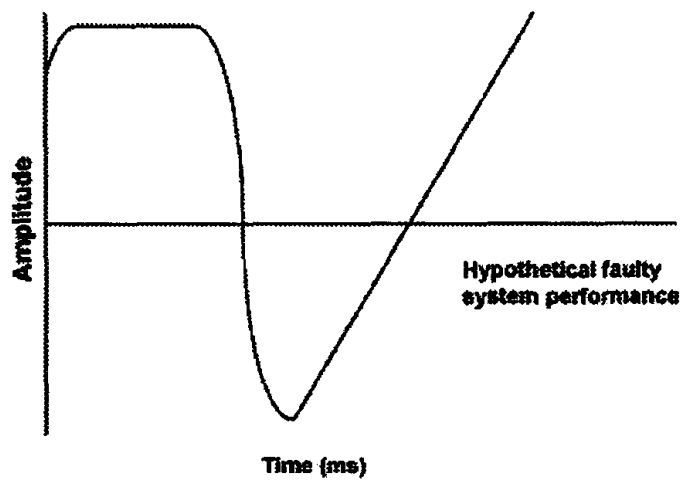

Figure 3C. System Non-Functional, Deteriorated To Failed Condition (3A, 3B, 3C Hypothetical Response)

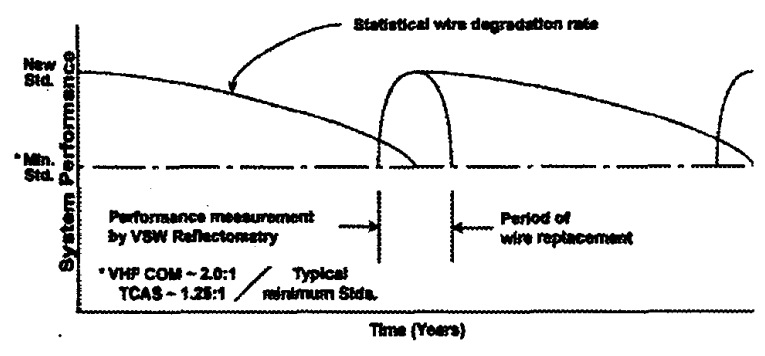

Figure 4. Anticipated Remaining Useful Life

generate remaining useful life. This information can be useful in minimize such business factors as gate holds in the commercial sector. See [11] Figure 4, 5 \& 6 for actual test traces and setup. 


\section{Expanding the Utility of Advanced Tooling}

With the integration of a hardened laptop and the appropriate software packages to either the automatic test equipment (ATE) or the VSWReflectometer a completely new world for testing opens up. (This is not quite ready for the market yet) The test capability expands to having a research project capability for the system being tested. At the RE's fingertips is enough data and information to do a complete set of diagnostics checking systems performance and fault location, to accomplish an entire condition monitoring program requirement. The ATE comes into play during heavy maintenance. The software displays on screen GO, Degraded Performance and NO Go for insulation condition, connectivity and continuity. A schematic can also be dragged down for reference and the direction \& distance of the fault noted on the drawing. A tool set defined for wire repair or change out can be displayed at the same time on the desktop with a click of the mouse.

\section{The Carrot and The Stumbling Block}

Aviation wiring carries with it special needs which seem not to be understood except by the aircraft owners and operators who must face the reality of business and mission needs, flight schedules, inadequate tooling which is adaptable to the specific needs of the industry and lack of training in modern electronics systems. These specialized needs have caused a gape between the needs of the aviation industry and the choice of tooling and support services offered.

For the flight line the need is for a simple and easy to use tool that requires minimal disruption and intrusion to the aircraft. In addition this tool(s) must not only be quick to setup, it must also correctly diagnose the fault, ascertain the fault location and failed part. Following the repair the tool must perform system performance verification to fleet standards and have collected systems performance data for comparison and later downloaded to the fleet database for further analysis.

For intermediate and depot maintenance the time pressure is only slightly relaxed and double ended testing will be required to obtain trends and useful remaining life or comparing wire systems design requirements to wire systems installation for a recent mod, etc. At this level of maintenance condition monitoring and comparison to baseline data takes place. Again wire/avionics systems performance measurement must be integrated into the overall maintenance plan and appear invisible to the overall operations.

The shortfall to most traditional tooling is its inability to be adapted to the environment it must be used, measurements that tooling must perform, intelligent processing of the measured data following the data measurements and downloading for further processing in support of the management of the aircraft health. Training is fundamental in understanding the total concept of diagnostics, prognostics, mediation, repair, verification, data management and health management of all electronic systems including the business model, risk analysis and decision theory. We are in the $21^{\text {st }}$ century and need to transition into addressing modern systems design and use [5,11\& 14 ].

\section{Recommendations}

- Participation in Awareness Seminar to understand why electrical and electronic systems fail

- Convert from time based maintenance to condition based maintenance or consider the increased risk and consequences of fire and wire event from not doing so

- Use NDT tooling that allows looking electronically into the systems performance

- Consider the use of NDT testing equipment that feeds performance data from the wire system and LRU/LRM simultaneously for complete systems performance testing and analysis

\section{Conclusions}

No single approach will provide all desired information concerning a wire system condition or performance necessary to support a given avionics system. Multiple technologies and software processing must be used. However, there are a set of approaches that when combined will provide a basic set of information describing the necessary status of the wire to make a sensible decision to 
whether the wire system is performing satisfactorily and is operating well within it's expected useful life.

Wire must be thought of as part of the avionics support system and during testing thought of as a system in itself. Wire supports the functions of the LRU, LRM, Display, etc. A wire system must have a very low risk or fire and wire event to be able to satisfactorily perform it's function. The risk of fire and wire event has been created from not keeping the installed wire that supports an aircraft's systems up to a pre-established standard that has yet to be defined and adopted. This standard is established and maintained through condition monitoring for the requisite performance standards of the systems it supports, i.e. allowable performance standards and failure rates etc. To maintain this standard wire must be monitored from within. That is to say the wire systems performance must be monitored electronically using several different technologies and the resulting information processed in such a way that the desired information for CBM is arrived at. To set this into place will not happen overnight

Awareness training and visual inspection is only the first line of defense. This is not good enough in it self. The avionics systems including the supporting wire function must be designed to perform it's intended function, then simulated either on a computer or in an avionics lab and performance measured electrically, electronically and functionally. This and the measurements taken on the aircraft establish the baseline measurement. The baseline measurement following the aircraft until the aircraft is retired. These records are kept in electronic media for rapid access and processing.

Contained in the GAO report to the Honorable Norman Y. Mineta, Secretary of Transportation and the Hororable Donald H. Rumsfeld, Secretary of Defense was a call for "The Aging Transport Systems Rulemaking Advisory Committee (ATSRAC) to create a working group to conduct visual (non-intrusive) inspections of 81 in-service aircraft that were over 20 years old. The results, released August 1, 2000 found that the majority of discrepancies with wire were in areas of frequent maintenance activity where wiring was unprotected from debris and fluid contamination. Table 1, an antidotal explanation of fault causation more precisely indicates $90 \%$ of all wire faults repeat aircraft to aircraft by kind and location. That $80 \%$ of those faults are human induced. Visual inspection is only $25 \%$ effective and can only be considered the first line of defense. To inspect the condition of aircraft wiring intrusive (nondestructive) automatic testing equipment (ATE) is used to test for conductivity, connectivity, conformity to design, insulation breakdown strength, insulation leakage current and faulted wire. A simpler and easy to use device is the voltage standing wave reflectometer (VSWReflectometer). This device tests for systems performance (good, degraded and failed) locates any fault in feet and inches from the test point, see Figure $3 \& 4$. Other information can be obtained by downloading the collected data into a notebook computer for processing other desired information concerning fleet-wide or specific aircraft systems data.

\section{Hypothetical Information - Gained From Data Processing (Limited Example)}

Potential information that may be desired from the data base. Simple programs may be developed for specialized software.

- Baseline Data

- Condition monitoring data and test methods

- Minimum performance criteria \& headroom

- Fault location if present

- Insulation breakdown strength \& standards

- Leakage current criteria \& max allowable

- Useful life

- Flight hours to next C or D

- Wire or component condition

- Standard repair time - hours

- Risk analysis and trend

- Antenna \& component condition

- Recommended test \& repair

- Time to test, repair \& validate, MH per system

The operator must conduct condition monitoring of the aircraft's wiring system for the life of the aircraft The bulk of the operators measurements will be made during the $C$ and $D$ checks and following an initial cleanup by visual 
inspection. CBM can be conducted It is anticipated that average wire, base on aircraft zone will vary from as low as 18 months to upwards of $10+$ years. However, there has not been enough data collected to project useful life for load distribution systems.

\section{References}

[1].Anderson, Donald, Paul Lapwood, Gil palafox, 2002. Aging Transport Systems Investigation,

Boeing Aero vol. 19, pages 8 - 19

[2] 1982. Investigation of Polyimide Wire Insulation Cracking Phenomenon, Laboratory Report Number 5191, Prepared for the Department of the Navy by Raychem Corporation,

[3] Campbell, F. J., Hydrolytic Deterioration of Polymer Insulation On Naval Aircraft, A. K. Brewer, R. J. Orr, T. A. Janicke, and A. M. Bruning, Navy

[4] Selenski, George A., Understanding Aging Systems Problems In Avionics, 1999. Third Joint FAA/DOD/NASA Conference on Aging Aircraft, Albuquerque, NM

[4] Larsen, Bill, Inspection Processes Must Compliment The Systems Inspected 2002.

IEEE/AIAA Digital Avionics Systems Conference, Irvine, $C A$

[5] Larsen, Bill, 2002. Enhanced Avionics Wiring Systems Integrity, available from author

[6] Teal, Chris, William E. Larsen, 2001. Balanced Circuits Improve Performance, IEEE/AIAA Digital Avionics Systems Conference, Daytona Beach, FL

[7] Larsen, William E., 2001. NDI For Electronic Systems Integrity, IEEE/AIAA Digital Avionics Systems Conference, Daytona Beach, FL

[8] Larsen, W.E., K.D. Cooksy, and John Zuk, 2001. Managing Aviation Safety Through Inspection and Information Technology, IEEE Industry Applications Magazine vol. 7, No.3, ISSN1077-2618, page 40-45.
[9] Teal, Christopher, William Larsen, 2002.

The Phenomenology of Wire, Dielectrics \& Frequency, IEEE/AIAA Digital Avionics Systems Conference, Irvine, $\mathrm{CA}$

[10] Truxal, John G., Control Engineers Handbook, McGraw-Hill Book Company, Library of Congress \# 57-6411

[11]Reference Data for Engineers, published by Howard W. Sams \& Co,

[12] Teal, Christopher, William Larsen, 2002. $A$ Planned Maintenance Program for Aircraft Wiring, IEEE/AIAA Digital Avionics Systems Conference, Irvine, $\mathrm{CA}$

[13] Teal, Christopher, Clay Satterlee, 2000. Managed Aircraft Wiring Health Directly Relates to Improved Avionics Performance: NDI/E Tests can Lead to Reduced Maintenance Costs and Improved Safety, ATA Annual Maintenance Conference, San Francisco, CA

[14] Teal, Christopher, Bill Larsen, 2002. Integration of Inspection Technology Aids in Avionics Systems Testing, IEEE/AIAA Digital Avionics Systems Conference, Irvine, CA

[15] Eaton, Navy (ret.) RADM Donald R., Armin M. Bruning, 1999. Economic Aircraft Wire Maintenance, Inspection and Repair: Performance Implications, 3rd. Joint FAA/DOD/NASA Conference on Aging Aircraft Conference, Albuquerque, $\mathrm{MN}$

\section{Disclaimer}

This is one of a series of papers describing potential improvement over existing practices in use today to help ensure the continued airworthiness of all aircraft. It should be considered as a possible addition to the process of wire husbandry and condition based maintenance. It is offered as a possible technical addition to the FAA's EAPAS program where applicable. 